\title{
PENGEMBANGAN BAHAN AJAR MODEL KOMIK MATEMATIKA ANAK BERKEBUTUHAN KHUSUS (ABK) SISWA
}

\author{
Chi Chi Karlina ${ }^{1)}$, Rosida Rakhmawati' ${ }^{2}$, Mujib ${ }^{3)}$ \\ Fakultas Tarbiyah dan Keguruan, Universitas Islam \\ Negeri Raden Intan Lampung \\ ${ }^{11}$ cicikarlina97@yahoo.com, ${ }^{2}$ rosidarakhmawati@radenintan.ac.id
}

\begin{abstract}
The use of media and materials teaching simple and sober make students gain values are very low. Based on the results of the pre-study were conducted in SLB Dharma Bhakti Pertiwi class VIII addressing 2 of 6 students only who have mastery in the learning of mathematics, as much as 65\% of participants learners memproleh value at under standard $K K M$. The purpose of research is namely to : (1) determine how eligibility development materials teaching comic math on Children with Disabilities Special which is determined in accordance with the purpose of education who want to achieve (2) determine whether the material teaching the learning of mathematics in the form of comic matemtatika is effective to apply the learning of mathematics. Research is using the methods of research ADDIE with 5 stages of development, namely (1) Analysis (2) Planning (3) Development Pr oduk (4) Application (5) Evaluation. The results of the research it is a matter of teaching the learning of mathematics in the form of comics mathematics on the child needs special (ABK) Student Class V III In Material the flat build.
\end{abstract}

Keywords: teaching materials, mathematical comics, children with special Needs (ABK).

\begin{abstract}
Abstrak
Penggunaan media dan bahan ajar yang sederhana dan seadanya membuat siswa mendapatkan nilai yang sangat rendah. Berdasarkan hasil pre-study yang dilakukan di SLB Dharma Bhakti Pertiwi kelas VIII hanya 2 dari 6 siswa yang memiliki penguasaan dalam pembelajaran matematika, sebanyak $65 \%$ peserta peserta didik memproleh nilai di bawah standar KKM. Tujuan dari penelitian ini adalah untuk: (1) mengetahui bagaimana kelayakan pengembangan materi pengajaran matematika komik tentang Anak Penyandang Cacat yang ditentukan sesuai dengan tujuan pendidikan yang ingin dicapai (2) menentukan apakah materi pengajaran pembelajaran pembelajaran matematika dalam bentuk komik matemtatika efektif untuk mengaplikasikan pembelajaran matematika. Penelitian ini menggunakan metode penelitian ADDIE dengan 5 tahap pengembangan, yaitu (1) Analisis (2) Perencanaan (3) Pengembangan $\mathrm{Pr}$ oduk (4) Aplikasi (5) Evaluasi. Hasil penelitian itu adalah soal pengajaran pembelajaran matematika dalam bentuk komik atematika tentang kebutuhan khusus anak (ABK) Siswa Kelas V III Dalam Materi flat build.
\end{abstract}

Kata kunci: bahan ajar, komik matematika, anak berkebutuhan khusus (ABK).

\section{PENDAHULUAN}

Pendidikan merupakan kebutuhan mutlak yang harus dikembangkan sejalan dengan tujuan pembangunan secara bertahap demi tahap. Pendidikan yang dikelola dengan tertib, teratur, efektif dan efisien (berdaya guna dan berhasil guna) akan mampu mempercepat jalannya proses 
pembudayaan bangsa yang berdasarkan pokok pada penciptaan kesejahteraan umum dan pencerdasan kehidupan bangsa yang sedang membangun seperti bangsa indonesia saat ini, sesuai dengan tujuan nasional seperti yang tercantum dalam alenia IV, pembukaan UUD 1945. Anak Berkebutuhan Khusus (ABK) secara singkat didefinisikan sebagai "anak yang dalam proses pertumbuhan atau perkembangannya mengalami kelainan atau penyimpangan (fisik, mental-intelektual, sosial, emosional), sehingga memerlukan pelayanan pendidikan khusus." Penyimpangan yang dimaksud dalam definisi tersebut termasuk tunanetra, tunarungu, tunagrahita, tunadaksa, tunalaras, lamban belajar, gangguan komunikasi, ADHD, dan Autisme.

Pembelajaran matematika di SLB sangatlah berbeda dengan pembelajaran matematika di sekolah formal sehingga membutuhkan perlakuan khusus. Pembelajaran matematika di SLB peserta didik juga memiliki tingkatan kemampuan yang berdeda yaitu tinggi, sedang,dan rendah sehingga setiap peserta didik tidak bisa menggunakan proses pembelajaran formal seperti peserta didik pada umumnya.

Berdasarkan hasil prasurvey hasil nilai ulangan harian siswa diketahui bahwa sebanyak $65 \%$ peserta didik memproleh nilai di bawah standar KKM. Rendahnya nilai matematika, karena saat proses pembelajaran selalu ada masalah dalam mempelajarinya. Hal tersebut juga terihat dari hasil wawancara dengan ibu Neneng selaku guru untuk kelas tunagrahita, dari hasil wawancara didapat bahwa faktorfaktor yang mempengaruhi dalam proses pembelajaran yaitu metode yang digunakan guru belum bervariasi, masih dengan metode-metode pendekatan seperti biasasnya, sehingga terkadang kurang memotivasi peserta didik dalam pemahaman materi yang dimaksudkan oleh guru. Walaupun kita mengetahui guru yang mengajar di SLB sudah pasti memerlukan keterampilan khusus untuk mengajar pada anak yang memiliki keterbatasan khusus, dengan pendekatanpendekatan yang tidak biasa dan tidak bisa sama pada anak normal pada umumnya.

2. Keterampilan mereka masih bisa diatih dan dikembangkan, bahkan bisa berprestasi. Salah satu pendorong dalam keberhasilan belajar adalah minat terutama minat yang tinggi. Minat itu tidak tumbuh dengan sendirinya akan tetapi banyak faktor yang dapat mempengaruhi minat belajar siswa, yaitu : motif, perhatian, dan bahan pelajaran.

Pembelajaran dengan menggunakan media komik ini dapat membuat peserta 
didik mudah dalam memahami materi pembelajaran karena desain media komik ini menarik minat perserta didik untuk belajar, dan materi matematika dimuat dan disusun semenarik mungkin agar mudah di pahami oleh peserta didik terutama peserta didik yang berkebutuhan khusus. Komik sebagai media pembelajaran, merupakan alat yang berfungsi untuk menyampaikan pesan pembelajaran.

\section{METODE PENELITIAN}

Jenis metode penelitian yang digunakan oleh penelitian ini yaitu metode penelitian Research and Development $(R \& D)$. Penelitian dan pengembangan $\mathrm{R} \& \mathrm{D}$ ini adalah metode penelitian yang digunakan untuk menghasilkan produk tertentu dan menguji keefektifan produk tersebut. Penelitian dan pengembangan ini mengacu pada model $A D D I E$ yang terdiri dari lima tahap. Kelima tahap tersebut adalah analyze, design, develop, implement, dan evaluate.

Penelitian dan pengembangan (R\&D) ini menggunakan yaitu data berupa kuantitatif dan kualitatif. Adapun teknik pengumpulan data dalam penelitian ini terdiri dari; wawancara dan angket atau kuesioner, tes, dan dokumentasi. Instrumen dalam pengumpulan data pada penelitian ini berupa test, angket dan instrument uji coba produk.

Teknik analisis data pada penelitian ini menggunakan teknik analisi deskriptif kualitatif yang memaparkan hasil pengembangan produk yang dikembangkan. Data yang diperoleh melalui instrumen uji coba dianalisis dengan menggunakan statistik deskriptif kualitatif. Analisis ini dimaksud untuk menggambarkan karakteristik data pada masing-masing variabel. Instrumen dalam penelitian ini menggunakan 4 jawaban, yaitu Sangat Baik (SB) diberi skor 4, Baik (B) skor 3, Cukup (C) skor 2, dan Kurang(K) skor 1

\section{HASIL PENELITIAN DAN PEMBAHASAN}

Hasil pengembangan yang dilakukan oleh peneliti ini menghasilkan media pembelajaran berupa komik matematika. Penelitian dan pengembangan ini dilakukan dengan menggunakan prosedur pengembangan Addie yang melalui 5 tahap pengembangan.

1. Tahap Analisis (Analyze)

2. Tahap Perancangan (Design)

3. Tahap Pengembangan (Development)

4. Tahap Implementasi (Implementation)

5. Tahap Evaluasi (Evaluation)

Diuji kelayakan nya menggunakan uji lapangan skala kecil dan uji lapangan skala besar. Berdasarkan keseluruhan hasil uji coba produk oleh para ahli dan 
penggunaan untuk nilai kelayakan media yang berupa media bahan ajar komik matematika di peroleh hasil sebagai berikut: 1) Hasil uji coba ahli materi mendapatkan hasil 3,39 dengan kriteria "Valid". 2) Hasil uji coba ahli media mendapatkan hasil 3,59 dengan kriteria "Sangat Valid". 3) Hasil uji kelayakan menurut penggunaan bahan ajar komik matematika oleh siswa, yaitu: Uji coba skala kecil memperoleh skor hasil ratarata sebesar 3,2 dengan kriteria "menarik". Uji coba skala besar memperoleh skor hasil rata-rata sebesar 3,3 dengan kriteria "sangat menarik".

\section{SIMPULAN}

Berdasarkan hasil penelitian dan pengembangan ini dapat disimpulkan bahwa: 1) Pengembangan bahan ajar komik matematika anak berkebutuhan khusus (ABK) siswa kelas VIII pada materi bangun datar mendapat nilai dengan kriteria valid berdasarkan penilaian validator ahli materi dan ahli media dan dapat diterima dengan baik oleh peserta didik Anak Berkebutuhan Khusus. 2) Bahan ajar komik matematika pada anak berkebutuhan khusus (ABK) siswa kelas VIII pada materi bangun datar mendapat respon sangat baik dengan kriteria sangat menarik berdasarkan respon siswa dan bahan ajar komik matematika pada anak berkebutuhan khusus (ABK) siswa kelas VIII pada materi bangun datar mendapat kriteria efektif dengan nilai effect size 0,610 kriteria menarik yang dilakukan pada uji lapangan yang oleh siswa kelas VIII tunagrahita SLB Dharma Bhakti Dharma Pertiwi Bandar Lampung.

\section{2) DAFTAR PUSTAKA}

Fuad Ihsan. (2013). Dasar-Dasar Pendidikan . Jakarta: Rineka Cipta.

Cahyaning Suryaningrum Dan Tri Muji Ingarianti. (2016). "Pengembangan Model Deteksi Dini Anak Berkebutuhan Khusus (Abk) Pada Tingkat Pendidikan Anak Usia Dini (Paud) Di Kota Malang". Jurnal Ilmiah Psikologi Terapan 4, No. 1 62-7 4.04.

Neneng Herawati. (2018). "Wawancara dengan peneliti, gurukelas TunaGrahita SLB Dharma Bhakti Pertiwi,". 25 mei 2018.

Rusmiati. (2017). "Pengaruh Minat Belajar Terhadap Prestasi Belajar Bidang Studi Ekonomi Siswa Ma Al Fattah Sumbermulyo". Ultility : Jurnal Ilmiah Pendidikan Dan Ekonomi, Vol.1, No.1.

Sugiono. (2013). Metode Penelitian Pendidikan Pendekatan Kuantitatif, Kualitatif, dan R\&D. Bandung: AlfaBeta. 